\title{
A Study on the Hardness of 7075 and 5052 Aluminum Alloys in the Equal Channel Angular Rolling Process
}

\author{
Saeed Saki ENTEZAMI ${ }^{1}$, Mohammad HonARPISHEH ${ }^{2, *}$ \\ ${ }^{1}$ Department of Mechanics, Jasb Branch, Islamic Azad University, Delijan, Iran \\ ${ }^{2}$ Faculty of Mechanical Engineering, University of Kashan, Kashan, Iran \\ *Corresponding author: honarpishe@ @ashanu.ac.ir, \\ Tel: ++98-31-55912404, Fax: ++98-31-55912424
}

\begin{abstract}
In this research, five strips, made of Al-7075 in the routes A and C and five strips made of Al-5052 in the route $\mathrm{C}$, were subjected to the equal channel angular rolling (ECAR) process during 5 passes in order to study the changes of hardness in the ECARed Al-7075-o and 5052 strips. The process of equal channel angular rolling is one of the severe plastic deformation processes which are used for strengthening metal sheets. The results of hardness test showed that by increasing the number of passes, surface hardness and hardness in the direction of thickness for ECARed Al-7075 alloy were increased $63 \%$ and $46 \%$ in the route $\mathrm{A}$, respectively and $51 \%$ and $30 \%$ in the route $\mathrm{C}$ respectively. Also, the hardness in the direction of thickness and surface hardness in Al-5052 alloy were increased $41 \%$ and $64 \%$, respectively.
\end{abstract}

Keywords: material strengthening, equal channel angular rolling (ECAR), severe plastic deformation (SPD), Al-5052, Al-7075.

\section{Introduction}

Aluminum is a soft and light metal which by the abundance of $8.13 \%$ is the third abundant element in the crust of earth and contains $7.3 \%$ of Earth's mass. Since 1930, aluminum alloys are considered as the first selective material for structural elements of airplane [1]. Aluminum alloys are divided to two classes of heat treatable and non-heat treatable [2]. The alloys of aluminum that have heat treating capability are hardened using natural or artificial aging treatment [3] and that category of aluminum alloys that are not capable of heat treatable are hardened using mechanical work. The alloys series $7 \mathrm{xxx}$ which their main alloying element is zinc, are heat treatable and the alloys series 5xxx which their main alloying elements is magnesium and manganese, are non-heat treatable. These alloys have good welding capability and have very good resistance in aquatic environment. SPD is an effective and efficient method for improving the properties of different metallic materials. Traditional methods of production like rolling or extrusion are restricted because of decreasing cross section in terms of applying high strains and can't satisfy the mentioned demands; while SPD processes don't have these limitations [4]. ECAR process is one of newest SPD methods that its apparatus and mold are shown in the figures (1) and (2). In this process, materials are compressed by rolling power to cross channels of mold [5] and in this way severe plastic strain is inserted to the material without change in cross section. 


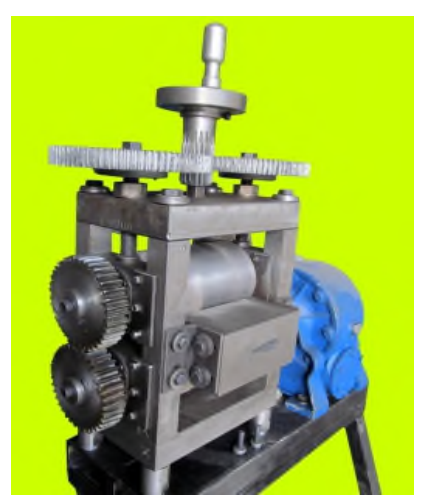

Figure 1: The used ECAR setup in this research

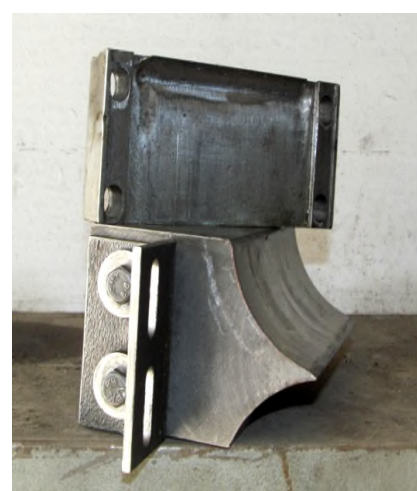

Figure 2:Exhibition of apparatus die used in this research

As this is a novel process, a few studies are performed on it until now. Nam et al (2003) studied the influence of chemical precipitation on the microstructure of the sheet made of ECARed A17050 [6]. Kim et al (2004) studied ferrite and pearlite particles in terms of microlithic perspective and band disappearance in steel sheet after ECAR process [7]. Cheng et al (2007) investigated the influence of channel looseness in ECAR process on crystalline directions of magnesium alloy sheet AZ31 [8]. Mohebali et al (2008) studied the properties of steel sheets St14 after applying ECAR process [9]. Habibi et al (2011) studied the influence of ECAR process on microstructure and electrical conductance of pure cupper [10]. Kvackaj et al (2012) investigated microstructure, mechanical properties and micro-hardness of pure cupper sheet which was ECARed during 1 to 13 pass stages [11] and in the same year, Mahmoodi et al studied residual stress in the direction of thickness for ECARed sheet AL 8053 [12]. Honarpisheh et al (2015) investigated the mechanical and metallurgical properties of AL/CU bilayer sheet produced by ECAR process [13]. With regard to the review of previous studies, there is no report on hardness changes in aluminum sheets 7075 and 5052 which are considered among highly used sheets in industry; therefore this research addresses the study of hardness changes in 7075-o aluminum sheets ECARed in the routes A and C and aluminum 5052 ECARed in the route $\mathrm{C}$.

\section{Materials and Methods}

In this research, two used alloys in the aerospace industries, Al-7075-o and Al-5052 were prepared as strips with dimensions $3 \times 5 \times 40 \mathrm{~mm}(\mathrm{~L} \times \mathrm{W} \times \mathrm{t})$. The process was performed on the Al-7075 samples in routes $\mathrm{A}$ and $\mathrm{C}$ and for $\mathrm{Al}-5052$ samples in the route $\mathrm{C}$ during five passing stages. In the route $\mathrm{C}$, the sample is rotated $180^{\circ}$ before feeding to mold, but it is not rotated in the route $\mathrm{A}$ and is fed to the mold again from the previous level. The chemical composition of used alloys was obtained by quantmeter method which are shown in tables (1) and (2). 
Table 1: Chemical composition of the Al-7075 alloy

\begin{tabular}{|c|c|c|c|c|c|c|c|c|c|c|c|c|}
\hline $\mathrm{Al}$ & $\mathrm{V}$ & $\mathrm{Co}$ & $\mathrm{Sn}$ & $\mathrm{Ti}$ & $\mathrm{Zn}$ & $\mathrm{Cr}$ & $\mathrm{Mg}$ & $\mathrm{Mn}$ & $\mathrm{Cu}$ & $\mathrm{Fe}$ & $\mathrm{Si}$ & Element \\
\hline 89.99 & 0.011 & 0.002 & 0.023 & 0.020 & 0.272 & 0.198 & 2.250 & 0.094 & 1.710 & 0.327 & 0.107 & $\begin{array}{c}\text { Alloy } \\
\text { composition }\end{array}$ \\
\hline
\end{tabular}

Table 2: Chemical composition of the Al-5052 alloy

\begin{tabular}{|c|c|c|c|c|c|c|c|c|c|c|c|c|}
\hline $\mathrm{Al}$ & $\mathrm{V}$ & $\mathrm{Co}$ & $\mathrm{Sn}$ & $\mathrm{Ti}$ & $\mathrm{Zn}$ & $\mathrm{Cr}$ & $\mathrm{Mg}$ & $\mathrm{Mn}$ & $\mathrm{Cu}$ & $\mathrm{Fe}$ & $\mathrm{Si}$ & Element \\
\hline 89.99 & 0.011 & 0.002 & 0.023 & 0.020 & 0.272 & 0.198 & 2.250 & 0.094 & 1.710 & 0.327 & 0.107 & $\begin{array}{c}\text { Alloy } \\
\text { composition }\end{array}$ \\
\hline
\end{tabular}

The results, selected for measuring hardness test and the sample of aluminum after process, are shown in figure (3). The used setup in this study includes two rollers and die in which the distance between the openings of two rollers is $2.97 \mathrm{~mm}$. The thickness of channel's input and output is equal to $3.2 \mathrm{~mm}$ and the angle of mold is $120^{\circ}$. Vickers micro-hardness test was implemented using Wilson apparatus under the load $25 \mathrm{~g}$ and the time $10 \mathrm{~s}$, and surface hardness test was implemented by Wilson apparatus under the load 32.25g using Brinell method. Before implementing the microharness test, in order to increase the accuracy of test, the surfaces of samples were properly polished by polisher 4000 and then using one-micron alumina solution.
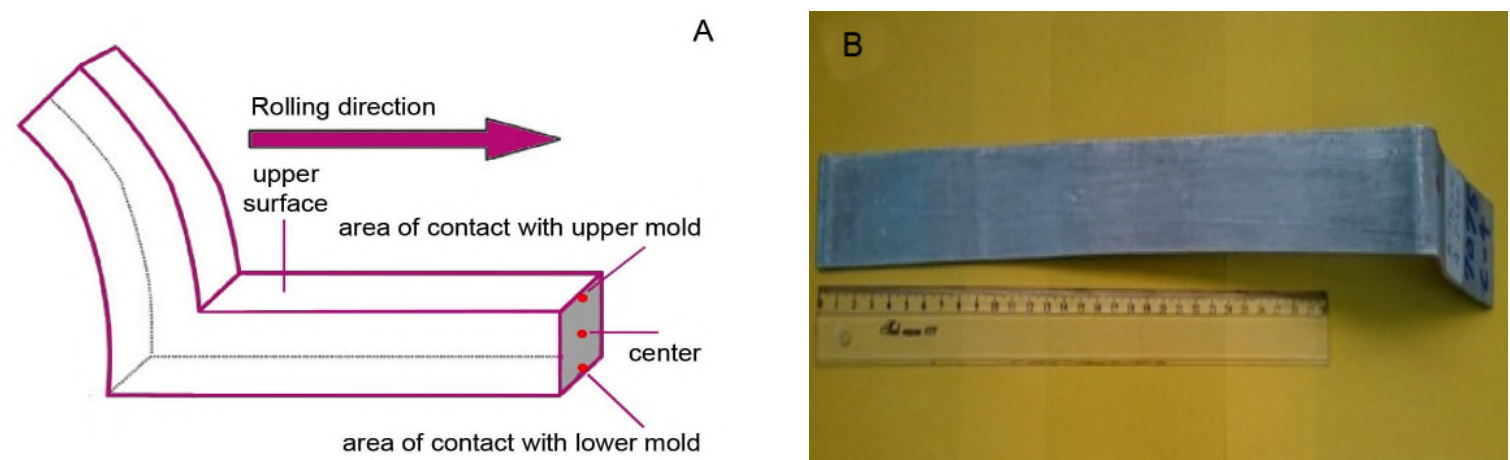

Figure 3: A) Selected points for sampling in hardness test B) Aluminum sample after process

\section{Results and Discussion}

In figure (4), engineering stress-strain graphs are shown for the Al-7075 alloys and Al-5052 alloys. As it can be seen, in the Al-7075 samples in both routes and also in the Al-5052 samples, yield strength and tensile strength are increased as a steep slope by increasing the number of passes. 
Obstacles in Development of Livestock Sector- Evidence from Kazakhstan
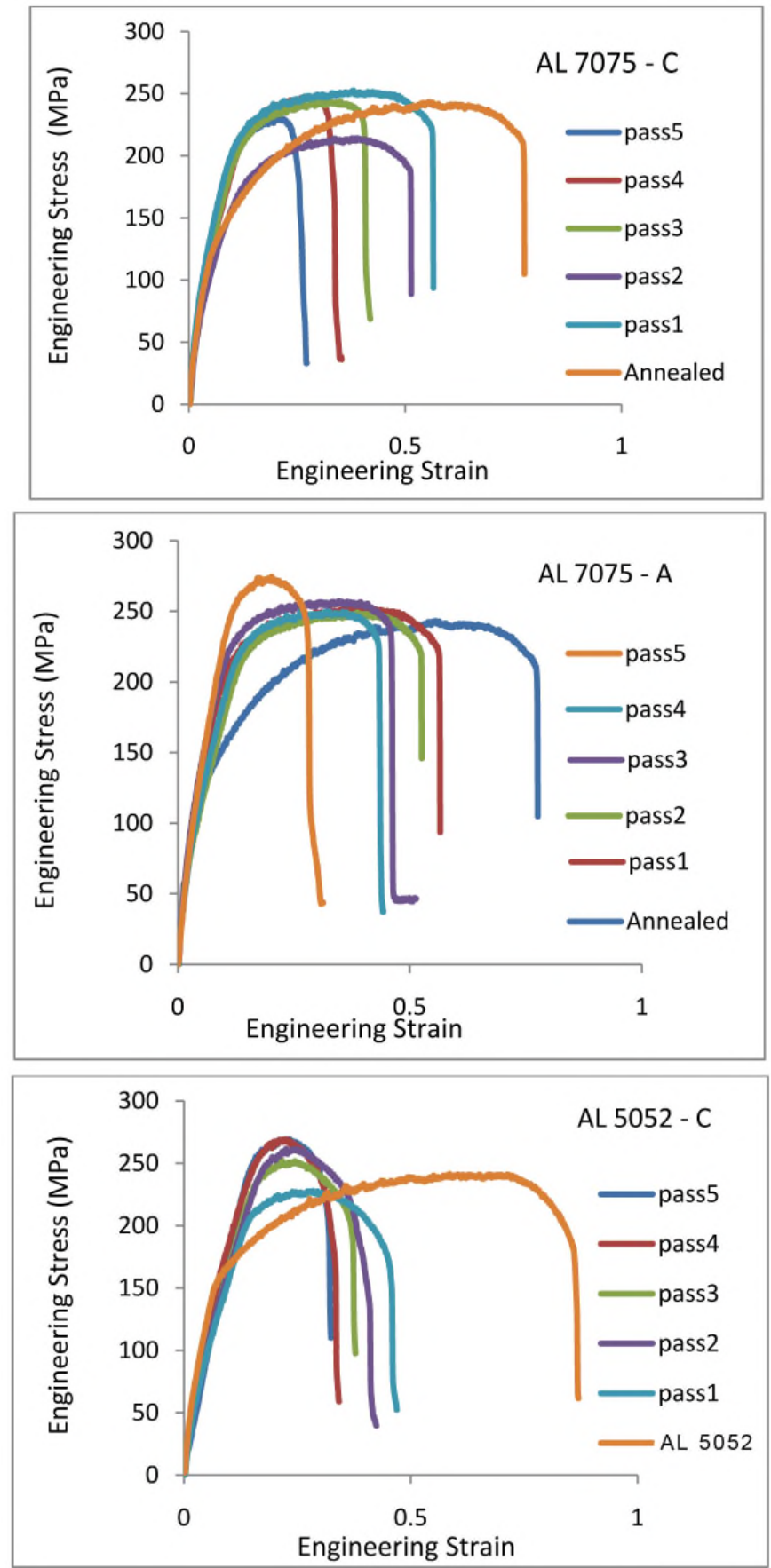

Figure 4: Engineering stress-strain diagram for the ECARed Al-7075 in the routes A and C, $\mathrm{Al}-5052$ in the route $\mathrm{C}$. 
Hardness changes in the direction of thickness are shown in three areas of near to upper surface, center and near to lower surface for aluminum 7075 in the route $A$ is shown in figure (5). As it can be observed, hardness in the points of the contact between sheet and roller or mold is higher and more homogenous than central part of sheet. The reason is the existence of friction in the contact position between sheet and roller or mold, and more inhomogeneous strain. The value of microhardness in the first pass is increased 30\% than the annealed sample. The reason for this increase in the hardness of strain mechanism is the hardness in primary pass. In the first pass, because of incurring high shearing strain, the density of dislocation is increased and the formation of secondary cells and also micro-structure and homogeneity of primary inhomogeneous and coarsegrained structure, causes the increase of micro- hardness. Micro-hardness is increased to its highest value i.e. $46 \%$ in the second pass.

In the third and fourth passes, the hardness is rarely decreased and in the fifth pass, hardness value is further increased. Decrease in hardness value can be because of the phenomenon of dynamic recovery. This phenomenon causes balance in dislocation density which causes the grains' boundaries to prevent from dislocations' movement and to decrease free route for the movement of dislocations.

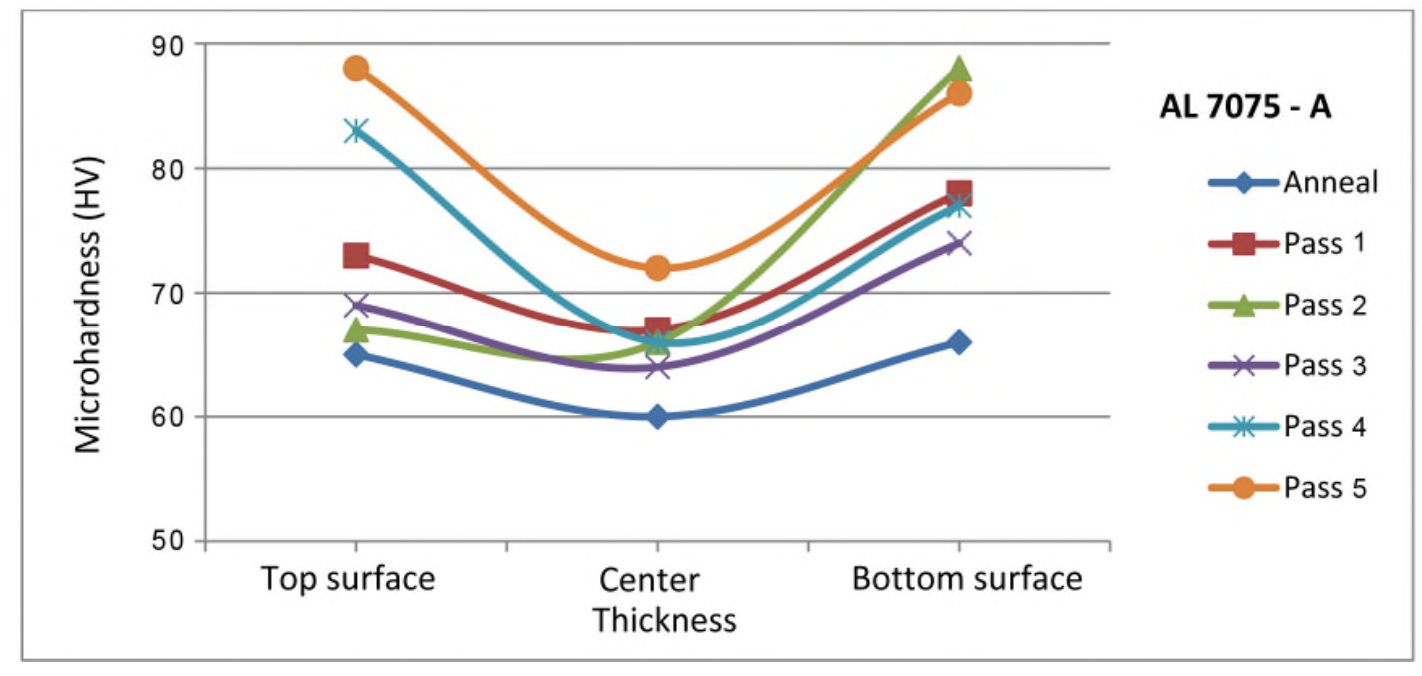

Figure 5: Hardness variations in the area of contact with upper die, central and lower die of ECARed Al-7075 in the route A

The results of surface hardness test for the sample of ECARed aluminum 7075 in the route A are shown in the figure (6). It can be observed that surface hardness is increased $20 \%$ in the first pass than the annealed sample and as it was mentioned this hardness increase can be because of work hardening mechanism in the first pass. Hardness continuously increases with the increase of the number of hardness pass which reaches to its maximum in the fifth pass i.e. 63\%. For the sample of ECARed 7075 in the route $\mathrm{A}$, the highest value of hardness is in the direction of thickness in the second pass and maximum surface hardness value is obtained in the fifth pass. This difference can be because of the increase in surface energy which is increased by the increase of pass stages. 


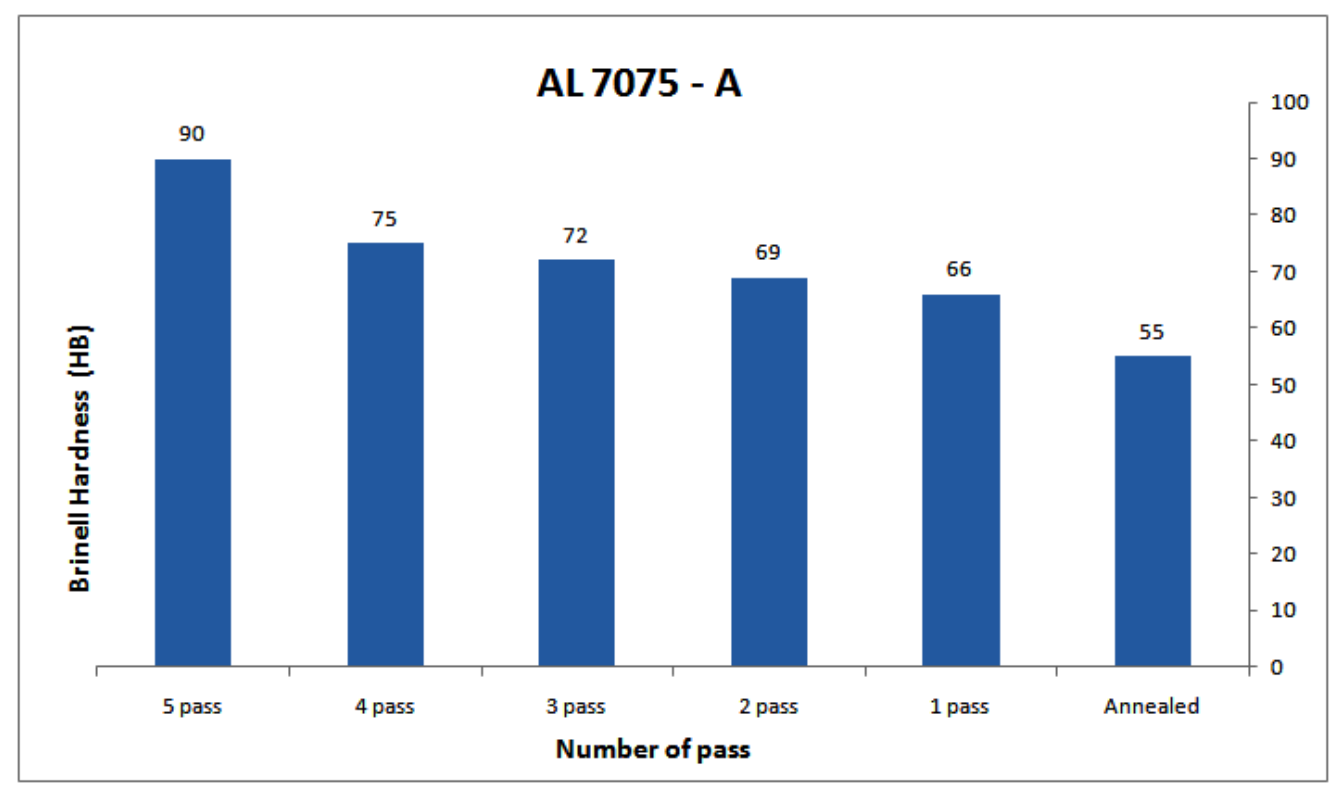

Figure 6: Changes of surface hardness for ECARed Al-7075 in the route A

Hardness changes in the direction of thickness in the three areas of near to upper surface, center and near to lower surface for ECARed Al-7075 alloy in the route C, are shown in the figure (7). In this route similar to route $\mathrm{A}$, because of the existence of friction in the contact location of sheet with roller or mold and more heterogeneous strain, hardness in the points of contact between sheet and roller or mold is higher and more heterogeneous than the central part of sheet. The value of micro-hardness in the first pass is increased 30\% than the value of annealed sample. The reason for this increase in hardness is similar to the route A of hardness strain mechanism in the primary pass. In the second pass to fifth pass, the value of hardness is not considerably changed and the value of hardness in it is decreased because of Dynamic recovery than the first pass. 
Obstacles in Development of Livestock Sector- Evidence from Kazakhstan

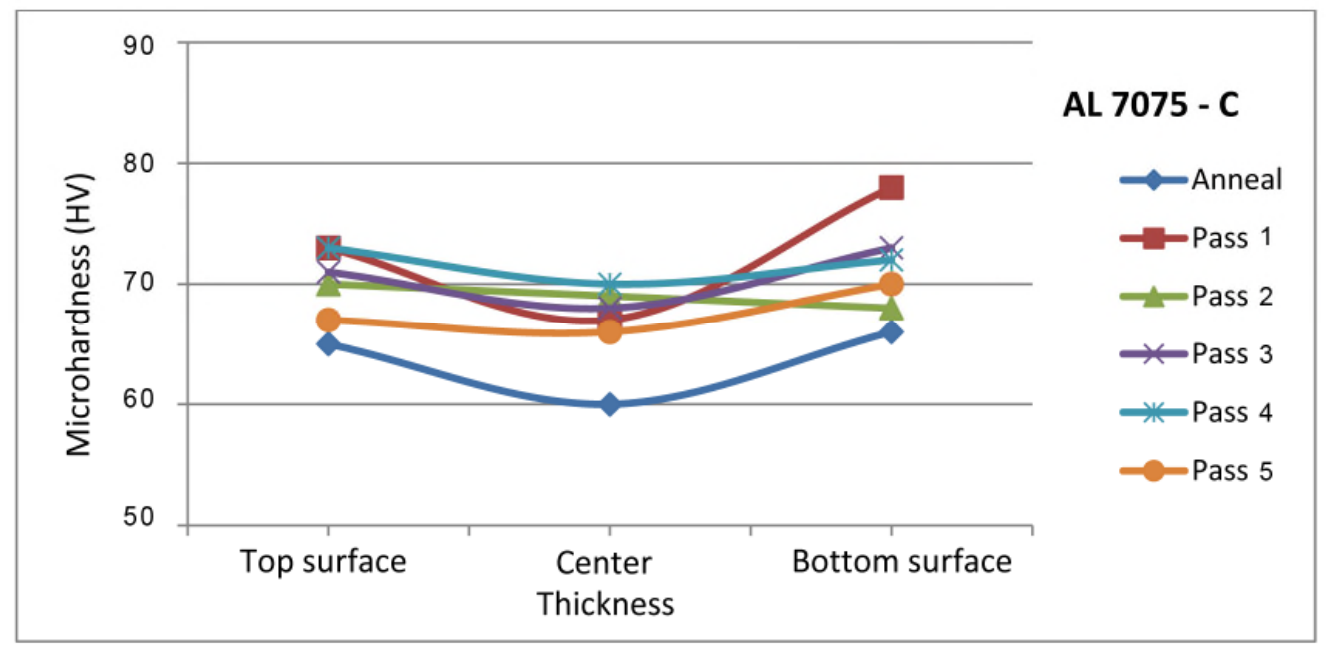

Figure 7: Hardness variations in the area of contact with upper die, central and lower die of ECARed Al-7075 in the route $\mathrm{C}$

The results of surface hardness test for the ECARed Al-7075 in the route $\mathrm{C}$ is shown in the figure (8). It can be observed that surface hardness is increased $20 \%$ in the first pass than the annealed sample, and as it was mentioned this increase in hardness can be explained by work hardening mechanism in the first pass. Hardness is continuously increased by the increase of passing number which reaches to its maximum in fourth pass i.e. $51 \%$ and thereafter, surface hardness is decreased by the occurrence of dynamic recovering phenomenon in fifth pass. For the ECARed Al-7075 samples in the route $\mathrm{A}$, maximum hardness value was obtained in the direction of thickness in the first pass and maximum value of hardness in the surface was obtained in fourth pass. As it was mentioned this difference can be explained by the increase of surface energy which is increased by the increase of pass stages.

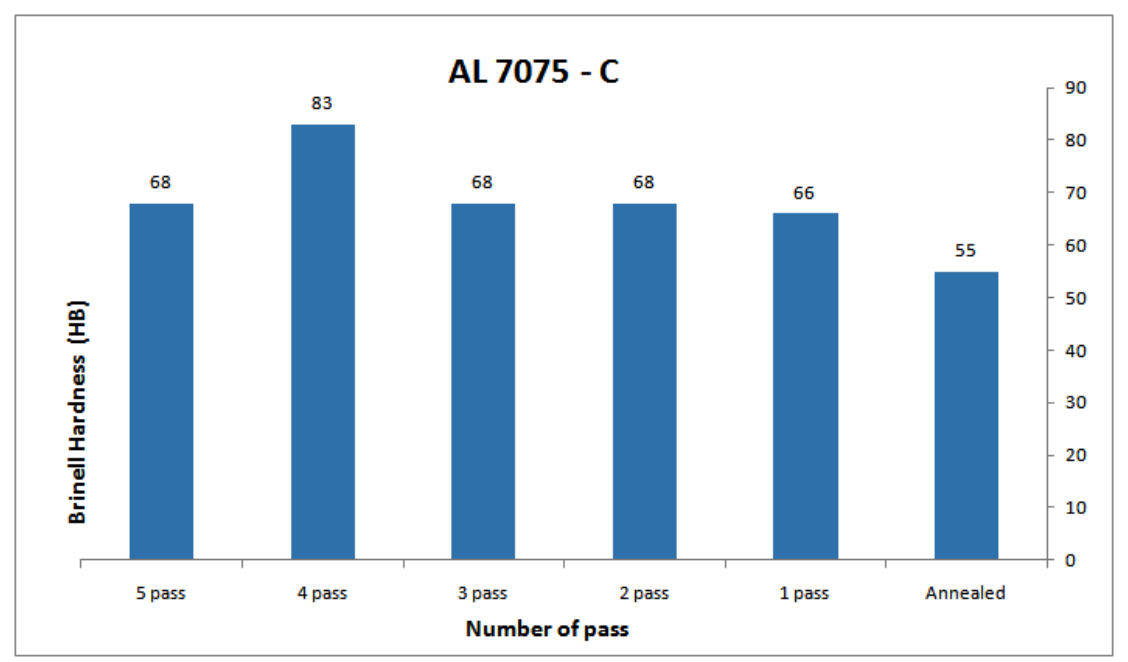

Figure 8: Changes of surface hardness for the ECARed Al-7075 samples in the route C. 
In the comparison of obtained hardness in two routes of $\mathrm{A}$ and $\mathrm{C}$ for $\mathrm{Al}-7075$, there is no impressive difference. Hardness changes in the direction of thickness are shown in figure (9) for three areas of near to upper surface, center and near to lower surface for ECARed aluminum 5052 in the route C. Hardness behavior in this alloy also is according Al-7075 alloy. The value of microhardness in the first pass is $46 \%$ increased than the value of micro-hardness in the annealed sample. The reason for this increase in hardness is hardness strain mechanism in the first pass. In the second pass, the value of hardness is not considerably changed but in the third pass, hardness reaches to its maximum i.e. $64 \%$. In the next passes, the value of hardness is decreased because of dynamic recovery.

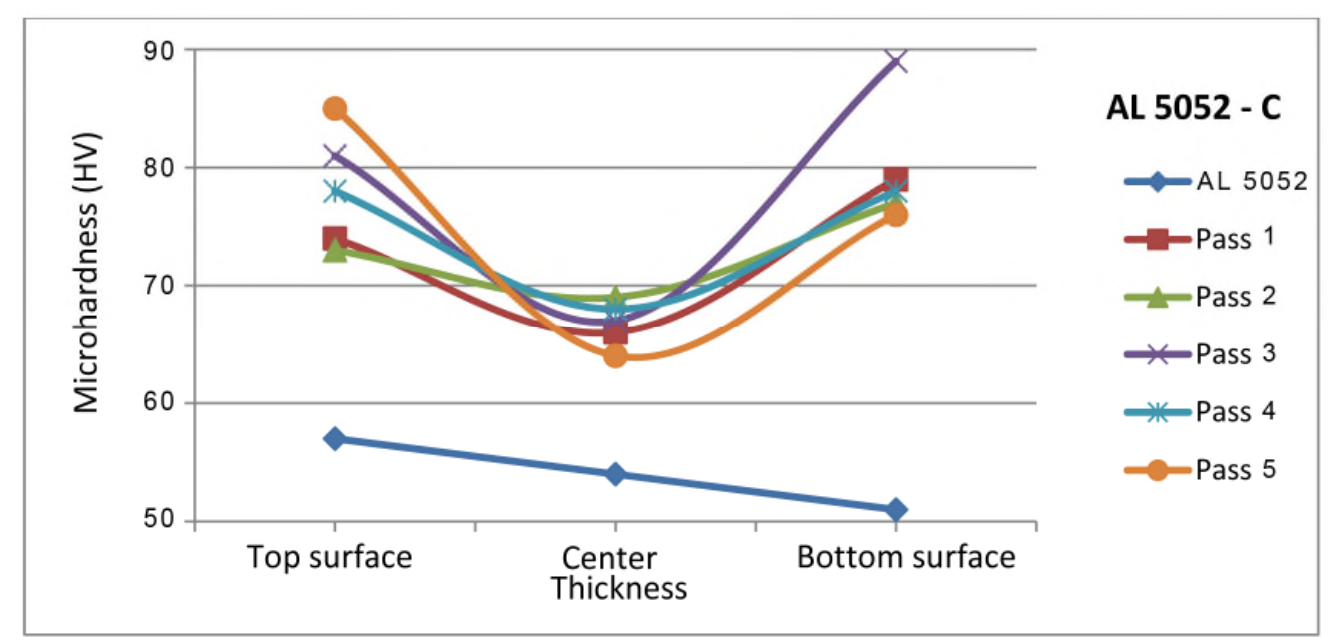

Figure 9: Hardness variations in the area of contact with upper die, central and lower die of ECARed Al-5052 in the route C

The results of surface hardness test for the ECARed Al-5052 samples in the route C are shown in the figure (10). It can be observed that surface hardness is increased $32 \%$ in the first pass than the annealed sample and as it was stated this increase in hardness can be explained by work hardening mechanism in the first pass. Hardness is continuously increased by the increase of pass number which is reached to its maximum value i.e. $41 \%$ in the fifth pass and thereafter surface hardness is decreased because of dynamic recovery occurrence in fifth pass. For the ECARed Al-5052 samples in the route $\mathrm{C}$, maximum hardness value was obtained in the direction of thickness in third pass and maximum value of hardness in surface was obtained in the fifth pass. This difference can be explained with the increase of surface energy which is increased by the increase of pass stages. 


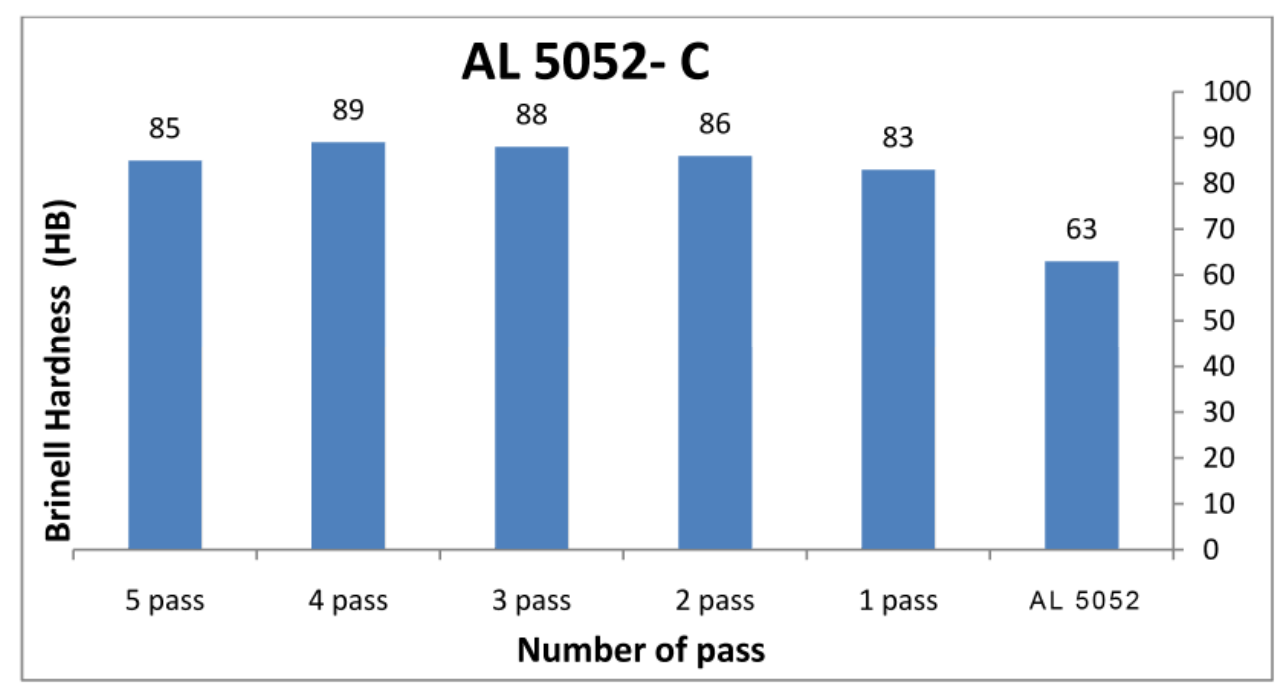

Figure 10: Changes of surface hardness in terms of pass number for the ECARed Al-5052 in the route $\mathrm{C}$

The increase of hardness influenced by ECAR process is reported for Al-7075 alloy in the reference [7]. As it can be seen in figure (11-a), hardness value in the annealed sample is increased $60 \mathrm{HV}$ to $100 \mathrm{HV}$ in Al-7050 alloy. In the figure (11-b) also the comparison of surface hardness and hardness in the direction of thickness is shown for Al-1100 in which surface hardness and hardness in the direction of thickness is increased by the increase of pass number. Also it can be observed that higher values are obtained for surface hardness than hardness in the center of thickness.

Obstacles in Development of Livestock Sector- Evidence from Kazakhstan
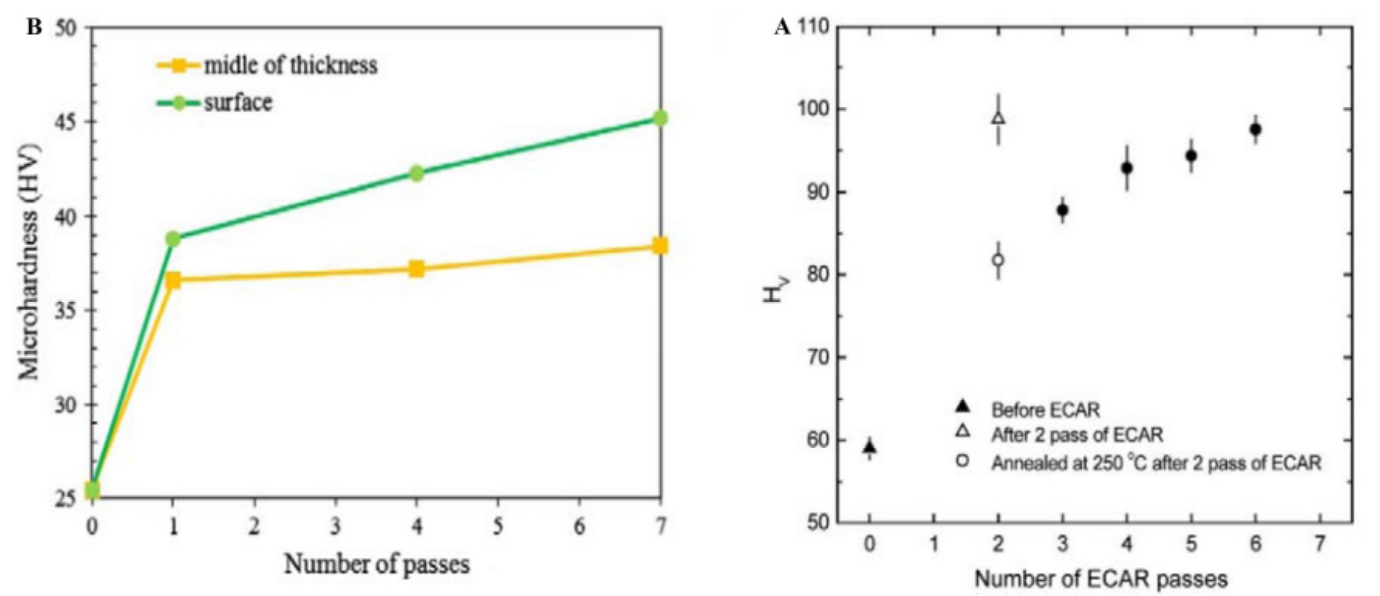

Figure 11: a) changes of micro-hardness in terms of the number of pass for Al-7075 [7], b) microhardness changes in surface and thickness for Al-1100 alloy in terms of pass number [14] 


\section{Conclusion}

In this research, the influence of ECAR process on the hardness changes of aluminum alloys 7075$\mathrm{O}$ and 5052 was investigated during which it became clear that by the increase of pass number in process, the hardness of samples increases and whatever we get more close to the surface of sample from center, the value of hardness is increased. The results of hardness test showed that surface hardness and hardness in the direction of the thickness of Al-7075 alloy in the route A were increased $63 \%$ and $46 \%$ respectively, and in the route C, $51 \%$ and $30 \%$ respectively, and also hardness in the direction of thickness and surface hardness in alloy 5052 were increased $41 \%$ and $64 \%$ respectively which this increase in hardness is because of occurring high density of dislocations which form the wall of new grains.

\section{References}

[1] Starke, E. A and Staleyt, J. T, (1996), "Application of Modern Aluminum Alloys To Aircraft, 0376--0421(95)00004-6.

[2] Totten, G.E and MacKenzie, D.S, (2003), "Handbook of Aluminum Vol.7 Physical Metallurgy and Processes, Marcel Dekker.

[3] Gharebagh, Sh., Aghajani, H., (2011), The influence of two stage aging treatment on hardness and strength to corrosion in aluminum alloy $7075,12^{\text {th }}$ national conference of fabrication and production engineering, Iran, Tehran, The society of fabrication and production engineering of Iran, Technical department of Tehran University.

[4] Dadian, A., RezaeiZadeh, M., (2013), Severe plastic deformation to roll-out method, National conference of Mechanical engineering, Iran, Shiraz, International education and research institution, Kharazmi Safashahr

[5] Nakashima K and Horita Z, (2000), "Development of a multi-pass facility for equal-channel angular pressing to high total strains. Mater Sci Eng A, 281:82-7.

[6] Nam, CY. Han, JH, (2003), "Effect of precipitates on microstructural evolution of $7050 \mathrm{Al}$ alloy sheet during equal channel angular rolling". Mater Scieng A; 347, PP. 253-7.

[7] Woo, P. J. and Kim, J, (2004), "Grain Refinement Of Steel Plate By Continuous Equal-Channel Angular Process", Scripta Materialia, Vol 51, No. 2, pp 181-184.

[8] Cheng, Y.Q and Chen, Z.H, (2007), "Effect of channel clearance on crystal orientation development in AZ31 magnesium alloy sheet produced by equal channel angular rolling" Journal of Materials Processing Technology 184 (2007) 97-101.

[9] Mohebali, M and Shahriary,S, (2008), "Effect Of ECAR Process On The Properties Of St14 Steel Sheet", $4^{\text {th }}$ National Conference of Metals and Materials Forming (MATFORM), Sharif University of Technology.

[10] Habibi, A and Ketabchi, M, (2011), "Nano-Grained Pure Copper With High-Strength And High-Conductivity Produced By Equal Channel Angular Rolling Process", Journal of Materials Processing Technology, Vol. 211, No. 6, pp-1085-1090.

[11] Kvackaj T and Kovacova A, (2012), "TEM studies of structure in OFHC copper processed by equal channel angular rolling, Micron, Vol 43, PP- 720-724.

[12] Mahmoodi, M and sedighi, M, (2012), "Investigation of through thickness residual stress distribution in equal channel angular rolled Al 5083 alloy by layer removal techniqueand X-ray diffraction". Materials and Design 40, PP. 516-20. 
[13] Honarpisheh, M and Dehghania, M. (2015), "Investigation of Mechanical Properties of Al/Cu Strip Produced by Equal Channel Angular Rolling", Procedia Materials Science, 11, PP 1 - 5.

[14] Azimi and A, Tutunchilar, S, (2012), "Mechanical properties and microstructural evolution during multi-pass ECAR of Al 1100-O alloy", Materials and Design (42), PP 388-394. 